\title{
Residual Stress Measurement on Large Shafts
}

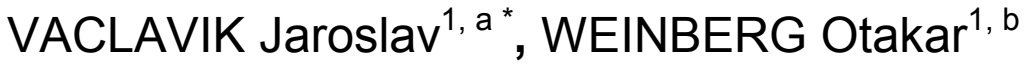 \\ ${ }^{1}$ VZU PIzen, Tylova 1581/46, 30100 PIzen, Czech Republic \\ avaclavik@vzuplzen.cz, bweinberg@vzuplzen.cz
}

Keywords: Residual stresses, hole-drilling method, ring-core method, shaft, axle, forging.

\begin{abstract}
The review and some experiences are given from measurement and evaluations of residual stresses on large shaft forgings and rail axles using the hole-drilling and ring-core straingauge methods, provided by Pilsner Research and Testing Institute, Czech Republic.
\end{abstract}

\section{Introduction}

Identification of residual stresses in the structure is very important for estimation of the structure service or residual service life. In many cases, it is necessary to measure the near-surface stresses, as there are responsible for the fatigue properties of the investigated parts. Sometimes the surface residual stresses give the information about inherent structure stresses.

The goal of this article is to compare the methods used for measurement of sub-surface residual stresses on large shaft forgings, especially the hole-drilling and ring-core methods, and show the suitability of their application on some service measurement examples.

\section{Brief Description of Testing Methodology on Large Shafts}

Testing shafts. The large shafts are produced by free forging from high strength vacuum degassed alloy steel, followed by controlled heat treatment (quenching and tempering). The proper manufacture of the semi-product is verified by the level of residual stresses on the representative piece of produced series. This level is derived from thermo physical calculation of residual stress distribution inside the cooled shaft. Approximately ten percent of the shaft yield point is allowed as residual stress in the shaft core, which corresponds to common value on the shaft surface. In that case the determination of residual stresses is used for controlling the manufacture process indirectly through the surface stresses. The allowable surface residual stress makes approximately $60 \mathrm{MPa}$ in most cases. This surface stress however may be influenced by the residual stress, induced by machining and has to be separated from them. By default, the measurement is performed at three cross-sections of the shaft, at drive end, middle part and non drive end, each place angularly turned $120^{\circ}$ from each other (Fig. 1).

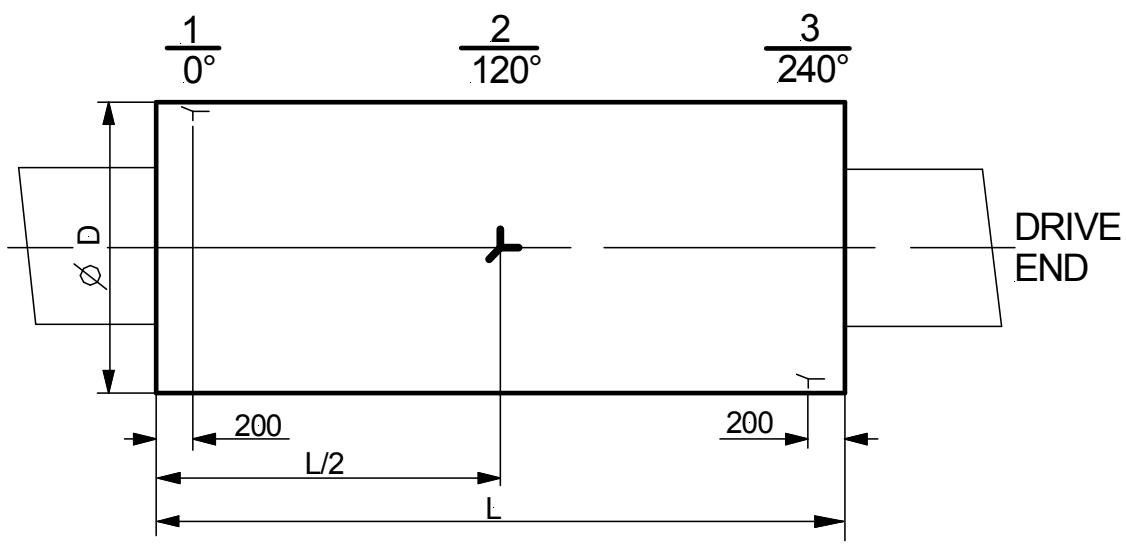

Fig. 1 Investigated points on representative shaft, $\mathrm{D}=1100, \mathrm{~L}=4000$, dimensions in [mm] 
For each measured point a narrow strip is induced on the shaft surface by fine 3-step turning to lower the machined residual stresses as low as possible. If the allowable value is not kept, additional heat treatment (stress relief annealing) is performed and the residual stress measurement is repeated.

Basically, hole-drilling [1] or ring core [2] methods are required for residual stress measurement. A few customers however prefer determination of tangential residual stresses made by measurement of distortion of circular ring, which is cut from the shaft (especially for the case of turbine shaft disks).

Hole-drilling method. By default 2-edge eccentric end mill ø4 mm and large $ø 13 \mathrm{~mm} H \mathrm{HBM}$ 3/120RY21 rosette are used for that type of measurement. Before each step the hole is pre-drilled with $ø 2 \mathrm{~mm}$. It was verified that using this procedure no significant stresses are induced during the low speed drilling. The evaluation is made according the standard ASTM E837 [1].

Ring-core method. The annular groove $\varnothing 14 / \varnothing 18 \mathrm{~mm}$ is machined with special tubular milling cutter in steps of $0.5 \mathrm{~mm}$ using strain gauge rosette TML FR-5-11 with integrated leading wires. The evaluation is made according simplified procedure in the layer 2 to $4 \mathrm{mms}$ under the surface [3].

\section{Sensitivity and Comparison of Hole-drilling and Ring-core Methods}

The hole-drilling method is not sensitive enough at required depths, to give the stresses with satisfactory accuracy using conventionally produced strain gauge rosette diameters. Comparison of absolute relieved strains for both ring-core and hole-drilling methods for uniform uniaxial stress of $60 \mathrm{MPa}$, is made in Fig. 2a) and curve derivatives are given in Fig. 2b).

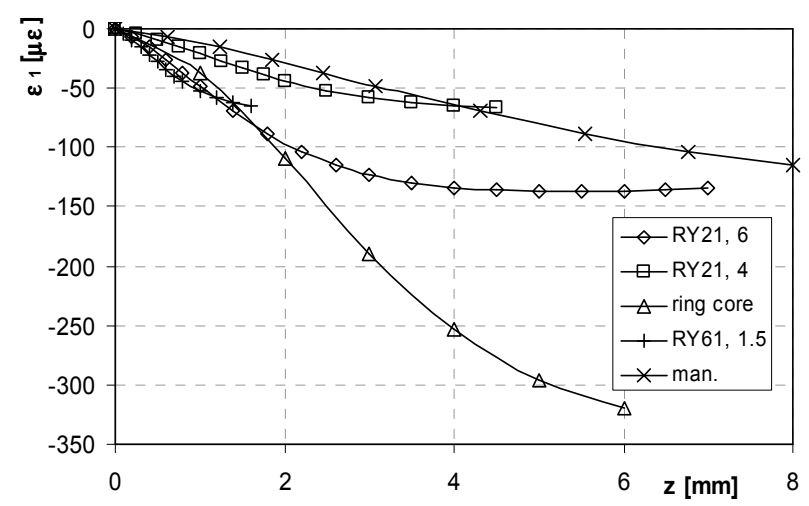

a)

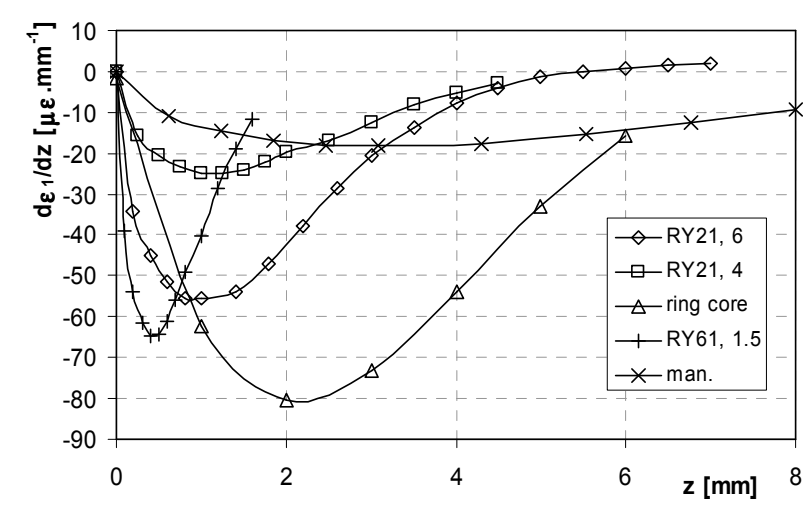

b)

Fig. 2 Comparison of relieved strains and their derivatives for uniaxial stress $\sigma_{1}=60 \mathrm{MPa}$

The most sensitive depth for hole-drilling method is $0.5 \mathrm{~mm}$ for small and $1 \mathrm{~mm}$ for large rosettes, (max slope of the relaxation curves). The depth of this peak does not change with increasing the hole diameter. The highest sensitivity of ring-core method is over $2 \mathrm{~mm}$ depths. Ring-core method is the best solution for residual stress measurement in the layer $2 \div 4 \mathrm{~mm}$, but for the layer $1 \div 2 \mathrm{~mm}$ the rosette RY21 also is recommended. Manually applied large rosette around the ring-core hole gives unexpected low sensitivity, comparable with RY21 rosette with the drilled diameter ø $6 \mathrm{~mm}$. Both charts are based on FEM calculations.

The influence of strain gauge rosette FR-5-11 TML misalignment was studied at uniaxial stress state $\sigma$ using FEM. Rosette was shifted from core centre in stress direction $\mathrm{x}$ and in perpendicular direction to the acting stress $y$ and the actual value of residual stress $\sigma_{\mathrm{e}}$ was calculated. The highest value represents core overlap with the rosette of $0.25 \mathrm{~mm}$. Obtained FEM results, the ratio of stress deviations $\Delta \sigma=\sigma-\sigma_{\mathrm{e}}$ to the nominal value $\sigma$, are given in Fig. 3a) to 3b).

The stress value is most sensitive to the rosette misalignment in direction of main principle stress. The zero sensitivity to rosette misalignment is approximately at the depth of $2.5 \mathrm{~mm}$. For the simplified method when only one value of residual stress is evaluated in the layer between 2 and 
$4 \mathrm{~mm}$ the error is less than $2 \%$ including the state, when the rosette carrier touches the edge of the drilled core.

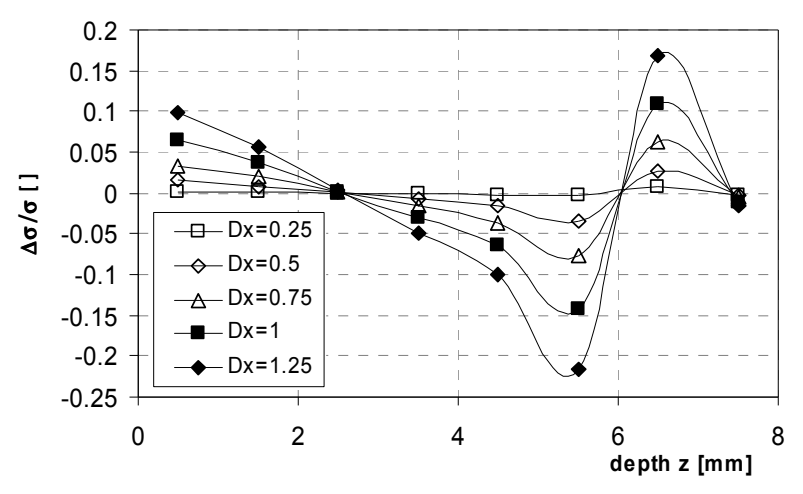

a)

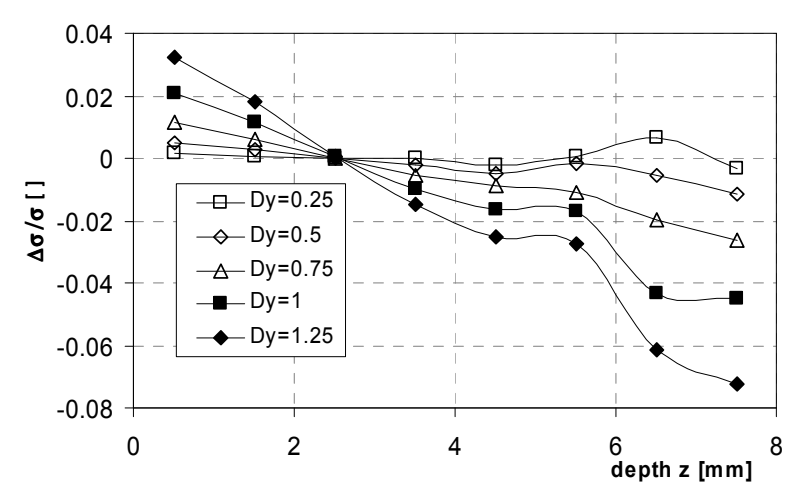

b)

Fig. 3 Stress relative errors due to rosette misalignment in longitudinal and transversal directions

\section{Results Obtained During Service Measurement}

Comparison of hole-drilling and ring-core methods. An example of measured relieved strains of shaft forging (material $25 \mathrm{Cr} 2 \mathrm{Ni} 4 \mathrm{MoV}$ ) after heat treatment, mean diameter $1100 \mathrm{~mm}$, is shown in Fig. 4a). Evaluated principal stresses along the depth using polynomial approximation of released strain derivatives and the average stress at layers between $2 \mathrm{~mm}$ and $4 \mathrm{~mm}$ are plotted in Fig. $4 \mathrm{~b}$. Here, the comparison is made with simplified method (column chart, marked 2-4). The comparison of data obtained from both ring-core and hole-drilling methods demonstrably show the higher sensitivity of ring-core method on real specimen.

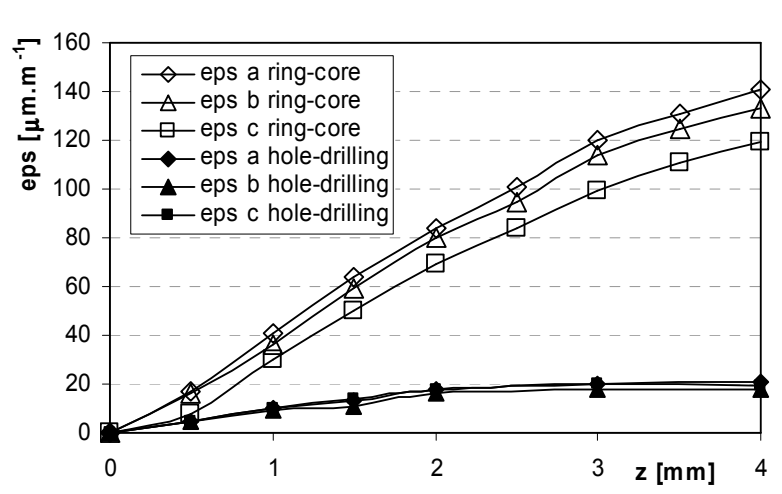

a)

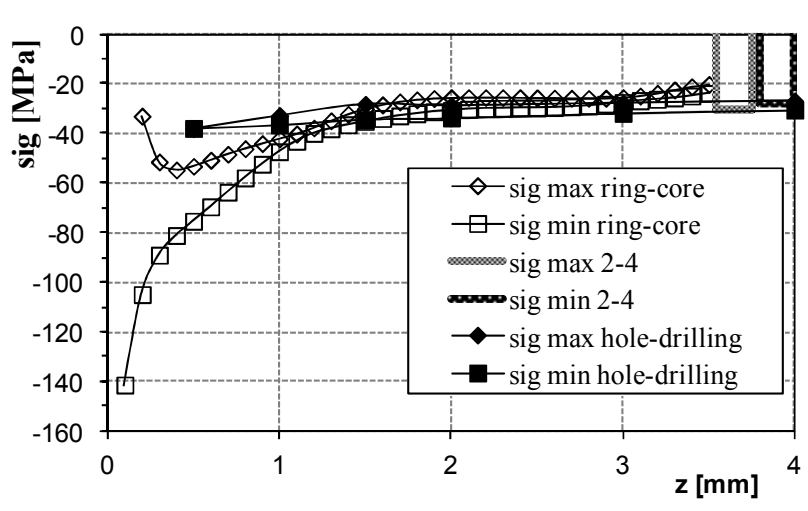

b)

Fig. 4 Released rosette strains a) and evaluated principal residual stresses b) using ring-core and hole-drilling strain-gauge methods

Separation of surface stresses. The goal was to separate the surface stresses, induced due to rough turning. The calculation using Tichonov regularization to smooth the residual stress profile by integral method was used [1]. The standard service test was made on turbine rotor forging, made from 28CrMoNiV59. The drilling was made in 20 equal steps up to $2 \mathrm{~mm}$. Some irregular steps were made up to $5 \mathrm{~mm}$ depth. Procedure for coefficients approximation, evaluating and smoothing residual stresses was made in MS Excel. This is suitable tool for matrix calculations and iteration procedure using solver for searching of optimum values for regularization factors $\alpha_{P}, \alpha_{Q}, \alpha_{T}$.

Corresponding percentage plot of released strain $p$ in comparison with that derived for uniform stress including deviation from uniform stress is made in Fig. 5. There is obvious, that the distribution of residual stresses under the surface is strongly affected with the depth. The residual 
stress evaluation using power series method at standardized equal depths is given in Fig. 6 before and after fine machining of shaft surface. The residual stresses drop under the allowable value of $60 \mathrm{MPa}$ after fine machining. However, the integral method enables to avoid the fine machining just evaluating the stress under the surface.

Except of standardized method (data smoothing from 20 steps), the evaluation was also made for six non-equal depths with the original integral method (error optimization according Zuccarello [4]). Following depths were used: $\{0.3 ; 0.7 ; 1.0 ; 1.5 ; 2 ; 3.0\} \mathrm{mm}$ (Fig. 7 - opt.). The comparison of evaluated principal residual stresses using power-series method, optimized integral method and smoothed integral method is made in Fig. 7.

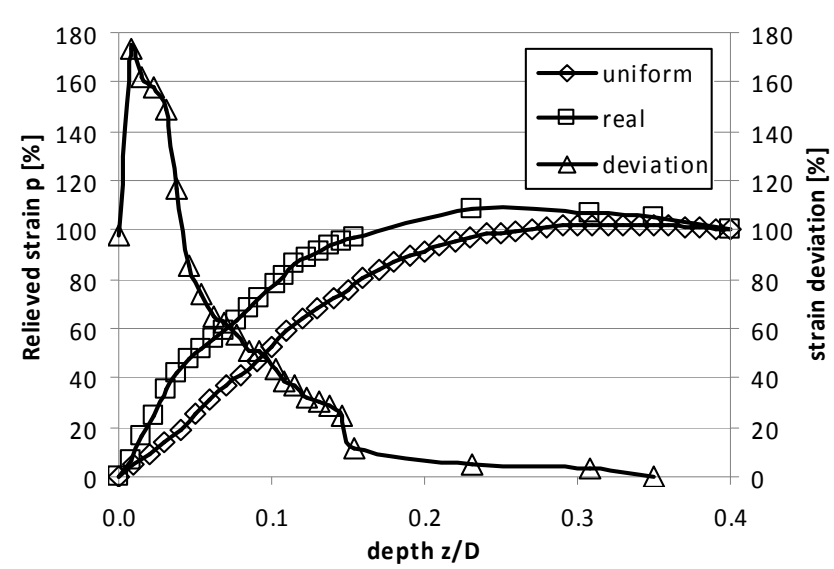

Fig. 5 Percentage relieved strain $p$ and deviation from strain caused by uniform stress

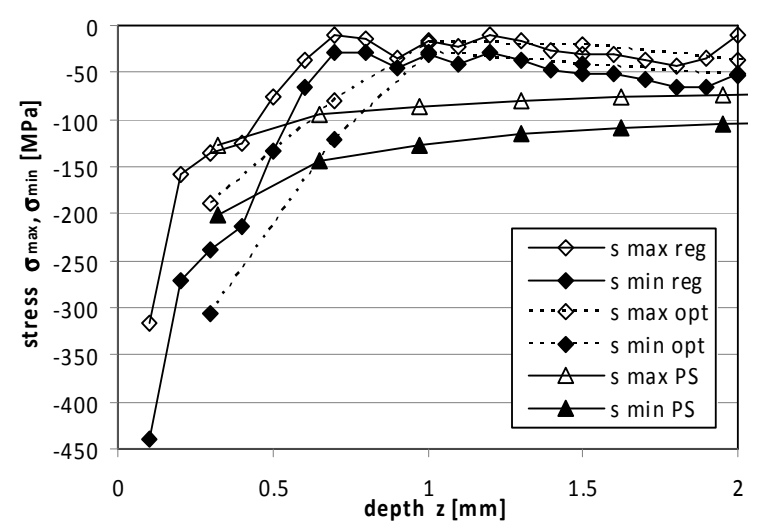

Fig. 7 Comparison of evaluated residual stresses

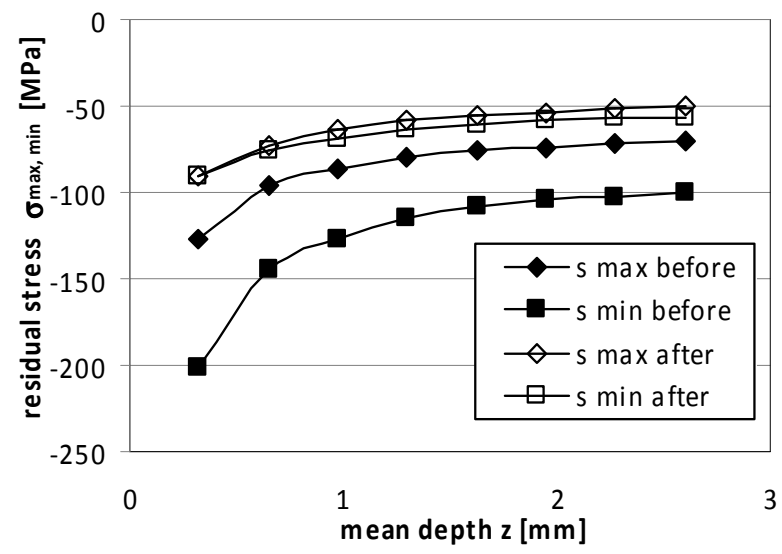

Fig. 6 Residual stresses before and after fine machining (power series method)

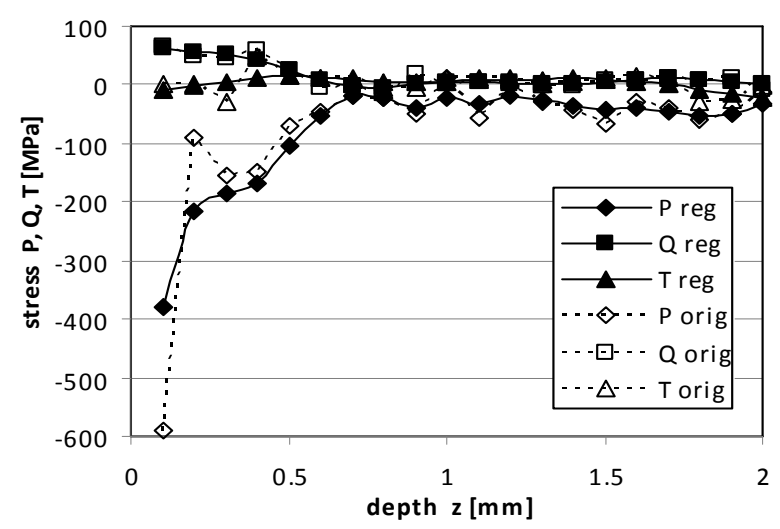

Fig. 8 Original and regularized stresses $P, Q, T$

The difference between original strains and those, backwards calculated after regularization, is very low. On the other hand, some difference is seen between original and regulated residual stresses, especially closely to the surface. The main influence for high principal stresses has the stress component $P$ for which the regularization factor is beyond expectation low in comparison with the other factors.

Residual stresses calculated for the identical depths are the same as for the power series method as for the non-regularized integral method. However after regularization, this first depth stress is substantially lowered (Fig. 8).

Very positive founding is, that the regularized residual stresses at the depth around $1 \mathrm{~mm}$ and deeper are comparable with those, computed for 6 optimum depths according Zuccarello [4]. Evaluation of residual stresses using power series method gives unrealistically high stresses. The influence of the machining goes to $0.75 \mathrm{~mm}$ depth, which is evident after comparison of the residual stress profiles before and after surface fine machining. 
Residual stresses on rail axles. The surface and sub-surface stresses and thickness of the surface layer work-hardened by roller peening (pressure force of the roller $F=30 \mathrm{kN}$ ) to increase the fatigue behavior were investigated on railway axle $\left(\mathrm{R}_{\mathrm{e}}=587 \mathrm{MPa}, \mathrm{R}_{\mathrm{m}}=718 \mathrm{MPa}\right)$, annealed and not annealed. The measurements were performed according standard EN 13261 using hole-drilling method.

The cylindrical surface of the axle in effected zones was carefully turned to 6 decreasing diameters (Fig. 9) to avoid inducing any additional residual stresses and at each step the residual stresses were determined. The goal was to determine the depth of the work-hardened layer. The values of residual stresses in principal directions in the depth of $0.5 \mathrm{~mm}$ at each turned surface for both annealed and not annealed axle are show in Fig. 10. The goal of this study was to estimate the depth of residual stresses, not the absolute value. That is the way some of presented values are not corrected to elasto-plastic stress state and seems to be higher than the elastic limit of the material. The strengthened rolled depth is $5 \mathrm{~mm}$ for non-anealed axle and $8 \mathrm{~mm}$ for annealed axle.

The residual stress sub-surface profile measured on as delivered axle is shown in Fig. 11. The residual stress curves represent combination of measurement using small HBM RY61 and large HBM RY21 strain gauge rosettes. Both raw stresses and stresses corrected to elasto-plastic stress state are presented.

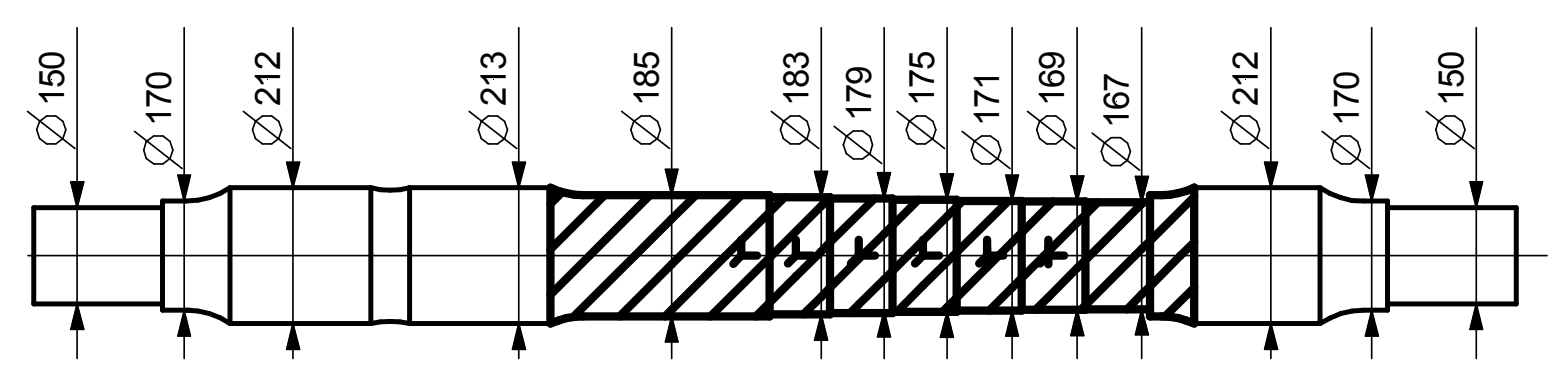

Fig. 9 Investigated rail axle - demonstration of investigated surfaces (hatched surface rolled)

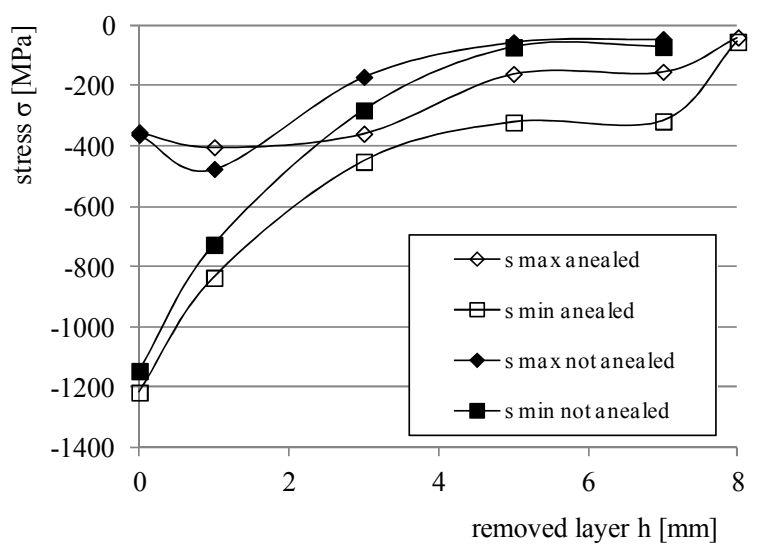

Fig. 10 Residual stress under rolled surface

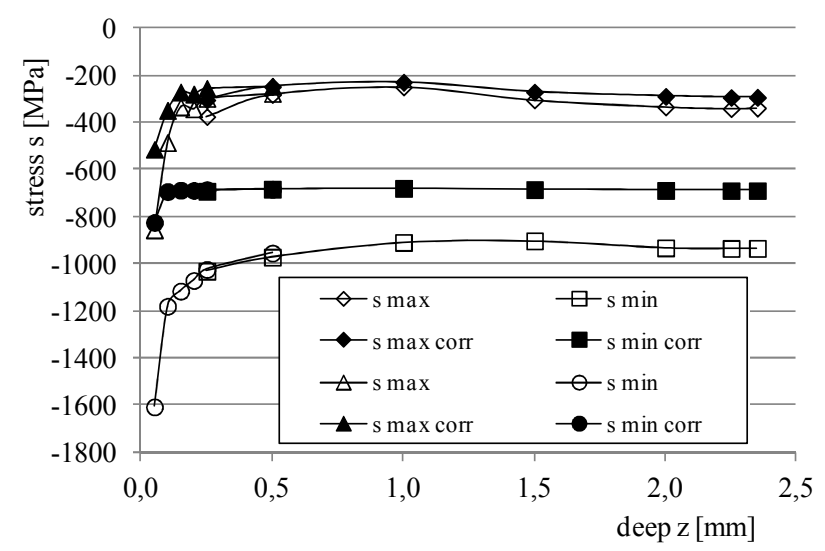

Fig. 11 Subsurface stresses of rolled axle

The influence of turning, annealing and final rolling to surface residual stress values of the rail axle during its manufacture is shown in Fig. 12. Finally, the distribution of apparent minimum principal residual stresses around the axle in its half-length section $2 \mathrm{~mm}$ under the surface is shown in Fig. 13 (this investigation is required according the standard EN 13 261). 


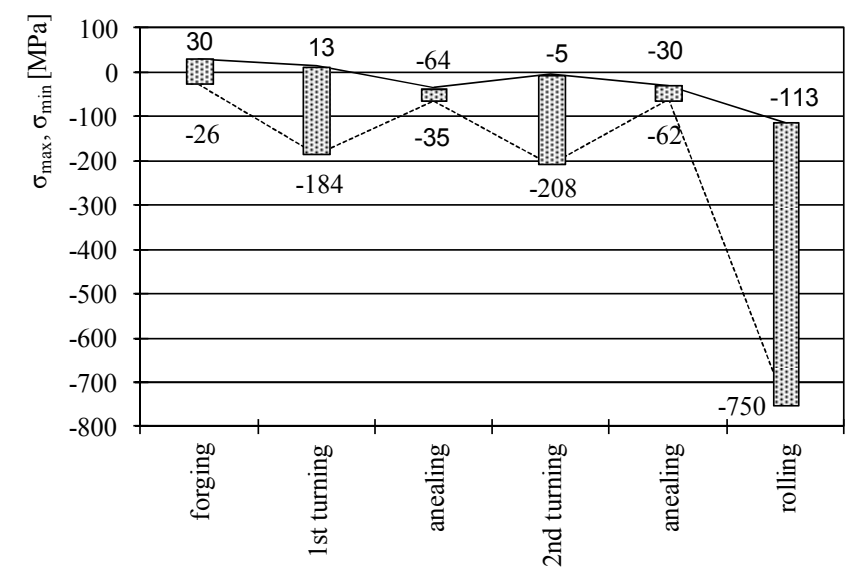

Fig. 12 Subsurface stresses during axle manufacture

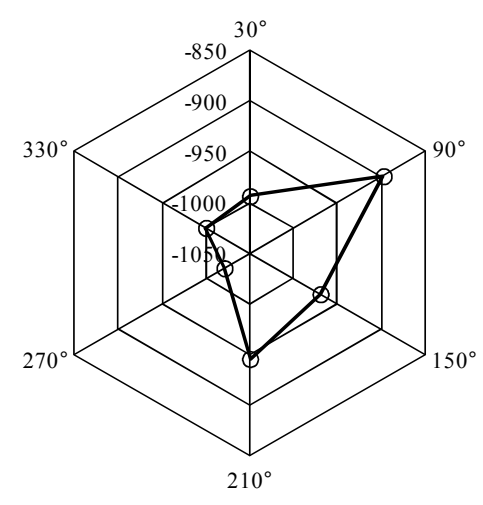

Fig.13 Angular distribution of residual stresses in the half length axle section

\section{Summary}

Investigation of residual stresses is performed often using hole-drilling strain gage method according ASTM E837 standard. The procedures described in this standard are applicable above all for small strain gauge rosettes and high speed drilling machines. Such application is suitable for measurement of surface stresses with respect to evaluate the fatigue behavior of the surface layer.

In some cases however, the subsurface stresses have to be evaluated to obtain the information about the detail internal stresses. It has been shown in this article that the hole-drilling method with standard low-speed end mill and the ring-core method still are suitable for this purpose, where it is necessary to cancel the influence of the machining to the surface residual stress. This is useful especially when it is not possible to release the stresses by cutting of the investigated detail.

Some examples were shown for investigation of subsurface stresses. It was also shown, that it is sufficient to go down the $1 \mathrm{~mm}$ depth to avoid the influence of standard machining stresses, which for the case of the turning have comprehensive character with the predominating tangential component.

The article has originated in the framework of the institutional support for the long-term conceptual development of the research organization.

\section{References}

[1] ASTM E837-13a, Standard test method for determining residual stresses by hole-drilling straingage method. September 2013.

[2] J.W. Böhm, E. Stücker, H. Wolf, RAM, 4, 1 (1988).

[3] PS-0.0001 Measurement of residual stresses in turbine and generator shaft. Inspection specification. Siemens AG - Power Generation. (2003).

[4] B. Zuccarelo, Optimal calculation steps for the evaluation of residual stresses by the incremental hole drilling method, Experimental Mechanics, 39 (1999), No.2, pp. 117-124.

[5] O.Weinberg, J.Václavík, J.Jankovec, P.Jaroš, S.Holý, Experimental Calibration of Computational Constants for Hole Drilling Method, Proceedings of 13th conference ICEM 13, Alexandroupolis, Greece, 2007, pp. 477-478.

[6] J.Václavík, O.Weinberg, P.Bohdan, J.Jankovec, S. Holý, Evaluation of Residual Stresses using Ring Core Method, Proceedings of 14th International conference ICEM14, Poitiers, France, 2010, pp. 44004. 